Tropical Journal of Pharmaceutical Research November 2016; 15 (11): 2467-2473

ISSN: $1596-5996$ (print); 1596-9827 (electronic)

(C) Pharmacotherapy Group, Faculty of Pharmacy, University of Benin, Benin City, 300001 Nigeria.

All rights reserved.

Available online at http://www.tjpr.org

Original Research Article

http://dx.doi.org/10.4314/tjpr.v15i11.23

\title{
Rapid validated liquid chromatographic method coupled with Tandem mass spectrometry for quantification of nintedanib in human plasma
}

\author{
Hany W Darwish ${ }^{1,2 *}$, Mohamed W Attwa ${ }^{1}$, Adnan A Kadi ${ }^{1}$ \\ ${ }^{1}$ Department of Pharmaceutical Chemistry, College of Pharmacy, King Saud University, PO Box 2457 Riyadh, 11451, Kingdom \\ of Saudi Arabia, ${ }^{2}$ Department of Analytical Chemistry, Faculty of Pharmacy, Cairo University, Kasr El-Aini Street, ET 11562 \\ Cairo, Egypt
}

*For correspondence: Email: hdarwish75@yahoo.com

Revised accepted: 8 October 2016

\begin{abstract}
Purpose: To develop and validate a fast, sensitive, and simple liquid chromatographic method coupled with tandem mass spectrometry for the determination of the potent tyrosine kinase inhibitor, ninetedanib (NTB) in plasma, utilizing cyclobenzaprine (CBP) as internal standard (IS).

Methods: Separation of the two components (NTB and CBP) was performed on a pentafluorophenyl $(P F P)$ reversed phase column $(50 \times 2 \mathrm{~mm}, 3 \mu \mathrm{m})$ at ambient temperature using isocratic elution with acetonitrile-water $(60: 40, \mathrm{v} / \mathrm{V})$ containing $0.01 \mathrm{M}$ ammonium formate buffer $(\mathrm{pH} 4.2)$ at a flow rate of 0.4 $\mathrm{mL} / \mathrm{min}$. NTB and CBP were monitored by a triple quadrupole tandem mass spectrometer with electrospray ionization source in the positive ion mode. The current method was validated following the European Medicines Agency (EMA) guidelines

Results: The proposed method allowed rapid and specific quantification of NTB in the calibration range of $2-150 \mathrm{ng} / \mathrm{mL}$ and determination coefficient of $\geq 0.999$. Intra- and inter-day accuracy and precision were $<4 \%$ in all cases.

Conclusion: The developed procedure is rapid, specific, reliable, and validated for quantification of NTB in human plasma, and thus can be applied efficiently for the analysis of clinical samples containing NTB.
\end{abstract}

Keywords: Nintedanib assay, Cyclobenzaprine, LC-MS/MS, Validation

Tropical Journal of Pharmaceutical Research is indexed by Science Citation Index (SciSearch), Scopus, International Pharmaceutical Abstract, Chemical Abstracts, Embase, Index Copernicus, EBSCO, African Index Medicus, JournalSeek, Journal Citation Reports/Science Edition, Directory of Open Access Journals (DOAJ), African Journal Online, Bioline International, Open-J-Gate and Pharmacy Abstracts

\section{INTRODUCTION}

Nintedanib (NTB, Figure 1(a)), as a powerful tyrosine-kinase inhibitor (TKI), acts by targeting numerous pathways for instance fibroblast growth factor receptor (FGFR), vascular endothelial growth factor receptor (VEGFR)-1n and others. NTB therapeutic action is mainly related to blockade of ATP- binding pocket that is found inside the cell [1]. NTB was approved by the FDA (2014) [2] and European Commission
(2015) for the management of idiopathic pulmonary fibrosis (IPF) [3-5]. Additionally, NTB was utilized simultaneously with docetaxel in treating non-small cell lung cancer (NSCLC) patients [6].

Upon reviewing the literature extensively, it was found that few articles were published for NTB quantification in rat biological fluids and tissues [7-9]. 
Accordingly, this study was devoted for quantification of NTB in spiked human plasma in presence of cyclobenzaprine (CBP; IS, Figure $1(b))$ in a very short run time (2 min), which permits the analysis of a lot of clinical samples containing NTB in a reasonable time. Additionally, the current procedure was fully validated following the EMA guidelines for validation of the bioanalytical method [10].

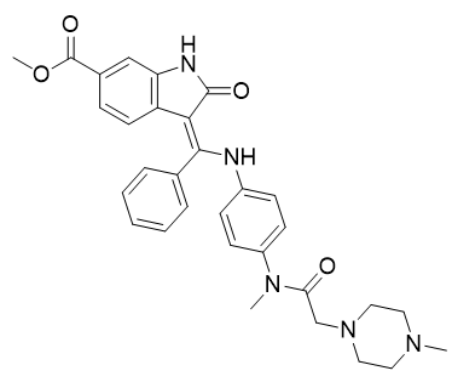

a)

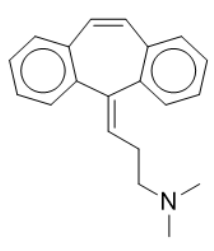

b)
Figure 1: Chemical structure of a) Nintedanib (NTB) and b) Cyclobenzaprine (CBZ; IS)

\section{EXPERIMENTAL}

\section{Chemicals and reagents}

Ninetedanib (NTB) reference powder was obtained from LC Laboratories (Woburn, MA, USA). Cyclobenzaprine (CBP; IS) reference powder, ammonium formate, HPLC-grade acetonitrile (ACN) and formic acid were procured from Sigma-Aldrich and WWR International (West Chester, PA, USA). Purified water was obtained from Milli-Q plus purification system, Millipore, Waters (Millipore, Bedford, MA, USA). Human plasma was kindly supplied by King Khaled University Hospital (Riyadh, KSA), after approved permissions from donners and it was kept frozen at $-70{ }^{\circ} \mathrm{C}$ until use.

\section{Instrumentation and conditions}

Chromatographic separation was conducted on an Agilent 1200 series system consisting of G1311A binary pump, G1322A degasser, G1367B HIP-ALS autosampler, G1316 thermostatted column compartment (column temperature was kept constant at $21 \pm 2{ }^{\circ} \mathrm{C}$ ), G1315 DAD detector and an Agilent 6410 QqQ LC/MS (Agilent Technologies, Palo Alto, CA, USA). Chromatographic separation was performed on Luna ${ }^{\circledR}$ PFP column $(50 \times 2 \mathrm{~mm}, 3$ $\mu \mathrm{m})$ (Phenomenex, Torrance, CA, USA). The flow rate was $0.4 \mathrm{mLmin}^{-1}$ with a mobile phase composed of $40 \%$ water containing 0.01 Molar ammonium formate buffer $(\mathrm{pH} \sim 4.2)$ and $60 \%$ acetonitrile (ACN). Sample injection volume was five microliter with a total run time of $2 \mathrm{~min}$. QqQ MS detector was utilized for detection of the analytes and operated with an ESI interface in the positive ionization mode. Nitrogen gas was utilized for desolvation (flow rate of $12 \mathrm{~L} / \mathrm{min}$ ) while nitrogen gas of high purity was utilized as collision gas (pressure $=55 \mathrm{psi}$ ). ESI source temperature was kept at $350{ }^{\circ} \mathrm{C}$, capillary voltage at $4 \mathrm{kV}$, and dwell time for each ion was $200 \mathrm{~ms}$. For quantification purposes, multiple reaction monitoring (MRM) was adopted for the transitions $540.3 \rightarrow 113$ for NTB, 276 $\rightarrow 231$ and $276 \rightarrow 84$ for CBP (IS). Fragmentor voltage was set to 135 and $140 \mathrm{~V}$ with collision energy of 25 and $20 \mathrm{~V}$ for NTB and CBP, respectively. Data manipulation and acquisition was achieved by Agilent MassHunter software.

\section{Preparation of standard solutions}

NTB stock standard solution $\left(1.0 \mathrm{mgmL}^{-1}\right)$ was prepared in DMSO. This stock solution was further diluted to prepare a working standard solution of $1 \mathrm{\mu gmL}^{-1}$. For preparation of CBP (IS) stock solution, reference CBP powder was solubilized in DMSO to produce a concentration of $0.1 \mathrm{mgmL}^{-1}$. One hundred $\mu \mathrm{L}$ of this stock solution was diluted to $10 \mathrm{~mL}$ with mobile phase producing a working solution of $1 \mathrm{\mu gmL}^{-1}$.

\section{Sample preparation procedure and construction of calibration curve}

Fifty microliter of CBP working standard solution (1 $\mathrm{\mu gmL}^{-1}$ ) was added to different aliquots of NTB working standard solution $\left(1 \mu \mathrm{gmL}^{-1}\right)$ and diluted to $1 \mathrm{~mL}$ with human plasma to prepare ten NTB concentrations: 2, 4, 6 (low quality control; LQC), 10, 30, 50 (medium quality control; MQC), 80, 100 and 120 (high quality control; $\mathrm{HQC)}$, and $150 \mathrm{ng} \mathrm{mL}^{-1}$.

For extraction of NTB and CBP from plasma matrix, one $\mathrm{mL}$ of $0.1 \mathrm{M} \mathrm{NaOH} /$ glycine buffer ( $\mathrm{pH}$-9) was added to $1 \mathrm{~mL}$ spiked human plasma and the samples were shaken for 60 seconds. Three $\mathrm{mL}$ of $\mathrm{ACN}$ was then added for protein precipitation. Precipitated proteins were removed by centrifugation at $14000 \mathrm{rpm}$ for 12 min at $4{ }^{\circ} \mathrm{C}$. Supernatants was filtered through a Millex-GP, $0.22 \mu \mathrm{m}$ syringe filter (Millipore, Billerica, MA, USA). The filtered supernatants were then loaded in the auto-sampler tray and volume of $5 \mu \mathrm{L}$ were injected into LC-MS/MS. Blank was prepared similarly by processing of blank human plasma with same procedure but using mobile phase instead of NTB aliquots, then tested to ensure the absence of interference from 
any endogenous compounds with NTB and CBP peaks. Calibration curve $(2,4,6,10,30,50,80$, 100,120 , and $150 \mathrm{ngmL}^{-1}$ ) were generated for spiked human plasma samples by drawing the peak area ratio of NTB to CBP (y axis) versus NTB nominal concentrations ( $x$ axis). Calibration samples' analysis at each concentration was attained in triplicates. Various parameters including intercept, determination coefficient $\left(r^{2}\right)$ and slope were utilized as tools for expressing linear regression. NTB concentrations in spiked plasma samples were calculated utilizing the corresponding linear regression equation.

\section{RESULTS}

Under the previously mentioned chromatographic conditions, NTB and CBP were well separated, and carryover effect was minimal in either blank matrix or blank samples containing CBP alone. Figure 2 showed overlaid chromatograms of calibration standard solutions of NTB in addition to CBP (IS) in plasma matrix samples.

NTB and CBP mass spectra were composed mainly of a single ion peaks at $\mathrm{m} / \mathrm{z} 540.3$ and 276.1 respectively. These ions were correspondent to the protonated parent ion. Isolation of $\mathrm{m} / \mathrm{z} 540.3$ (NTB) and 276.1(CBP) took place in the first mass analyzer (Q1) followed by fragmentation (q2) in the collision cell. By scanning of the fragments in the second analyzer, $\mathrm{m} / \mathrm{z} 113$ was detected for NTB while $\mathrm{m} / \mathrm{z} 231$ and 84 were detected for CPB as shown in Figure 3. For the quantification of NTB and $\mathrm{CBP}, \mathrm{m} / \mathrm{z} 113$ and 231 were selected respectively as daughter peak in MRM mode because they gave the highest signal intensity. While $\mathrm{m} / \mathrm{z} 84$ was utilized as a qualifier for CBP.

\section{Validation results}

\section{Specificity}

The current procedure showed high specificity for NTB determination as no interference was observed from expected components of plasma matrix at the retention time of NTB and/or CBP. The mass detector showed no carry over effect from samples. NTB and CBP were well separated under the optimized chromatographic conditions with retention times of 0.92 and 1.65 min, respectively.

\section{Linearity and sensitivity}

The linear regression analysis for the results was carried out using the least-square method. The results of six calibration curves showed linearity in the range of 2-150 $\mathrm{ngmL}^{-1}$ for NTB, with a determination coefficient $\left(r^{2}\right) \geq 0.9991$. The mean calibration curve of NTB standard solutions in plasma had the regression equation of $y=$ $2.5773 x+1.31$. The limit of quantitation $(L O D)$ and limit of quantification $(L O Q)$ were found to be 0.32 and $0.97 \mathrm{ngmL}^{-1}$ in plasma. The standard deviation values of each concentration point (six replicates) did not exceed $2.91 \%$. Calibration and quality control samples of NTB in human plasma (ten points) were back-calculated to ensure optimum performance of the proposed method. The precision and accuracy for NTB in plasma samples were found in the range of 0.85 to $5.39 \%$ and -3.86 to $2.34 \%$, respectively (Table 1).

\section{Precision and accuracy}

The current chromatographic procedure was confirmed to be precise and accurate using intraand inter-day precision and accuracy values of NTB QC samples. Percentage relative error (\% $\mathrm{RE}$ ) and percentage relative standard deviation (\% RSD) were used for evaluating accuracy and precision, respectively. The values for accuracy and precision lied into the suitable range following EMA guidelines [10] as displayed in Table 2.

\section{Stability}

Stability studies were performed on QC samples under various conditions as stated in Table 3 . The deviation of the results from the mean value of the samples was less than $3.15 \%$ for human plasma. Stability results displayed in Table 3 approved that plasma samples containing NTB can be kept under laboratory conditions with no observed decrease in NTB concentration.

\section{DISCUSSION}

Numerous experiments were tried for achieving maximum resolution and better separation for both NTB and CBP. The selection of the composition of the mobile phase was the corner stone of these trials; various percentages of ACN and water were tried. Addition of ammonium formate $(\mathrm{pH} \sim 4.2)$ to the mobile phase allowed easy ionization of NTB and CBP in addition to a better separation of the two peaks. Accordingly, the proportion of $40 \%$ of aqueous solution containing 0.01 Molar ammonium formate buffer $(\mathrm{pH} \sim 4.2)$ and $60 \% \mathrm{ACN}$ was utilized isocratically for good separation of the both analytes (retention times of 0.92 and 1.65 minutes for NTB and CBP, respectively), using the optimized LC-MS/MS condition. Run time for each run was not more than two min. 


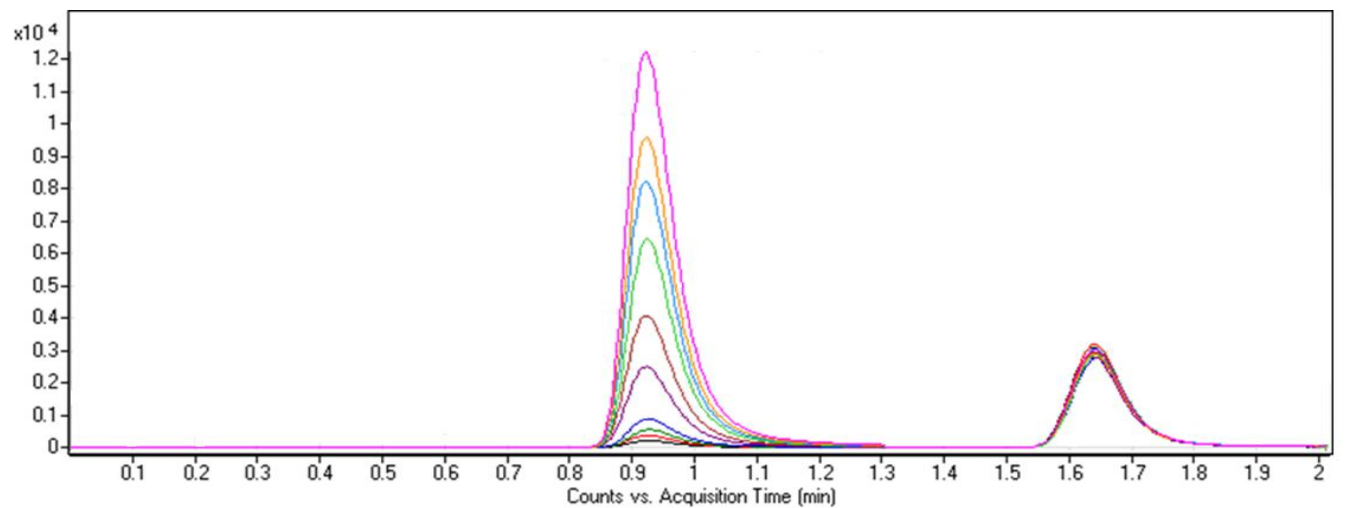

Figure 2: Overlaid MRM chromatograms of NTB and CBP (IS) in spiked human plasma samples
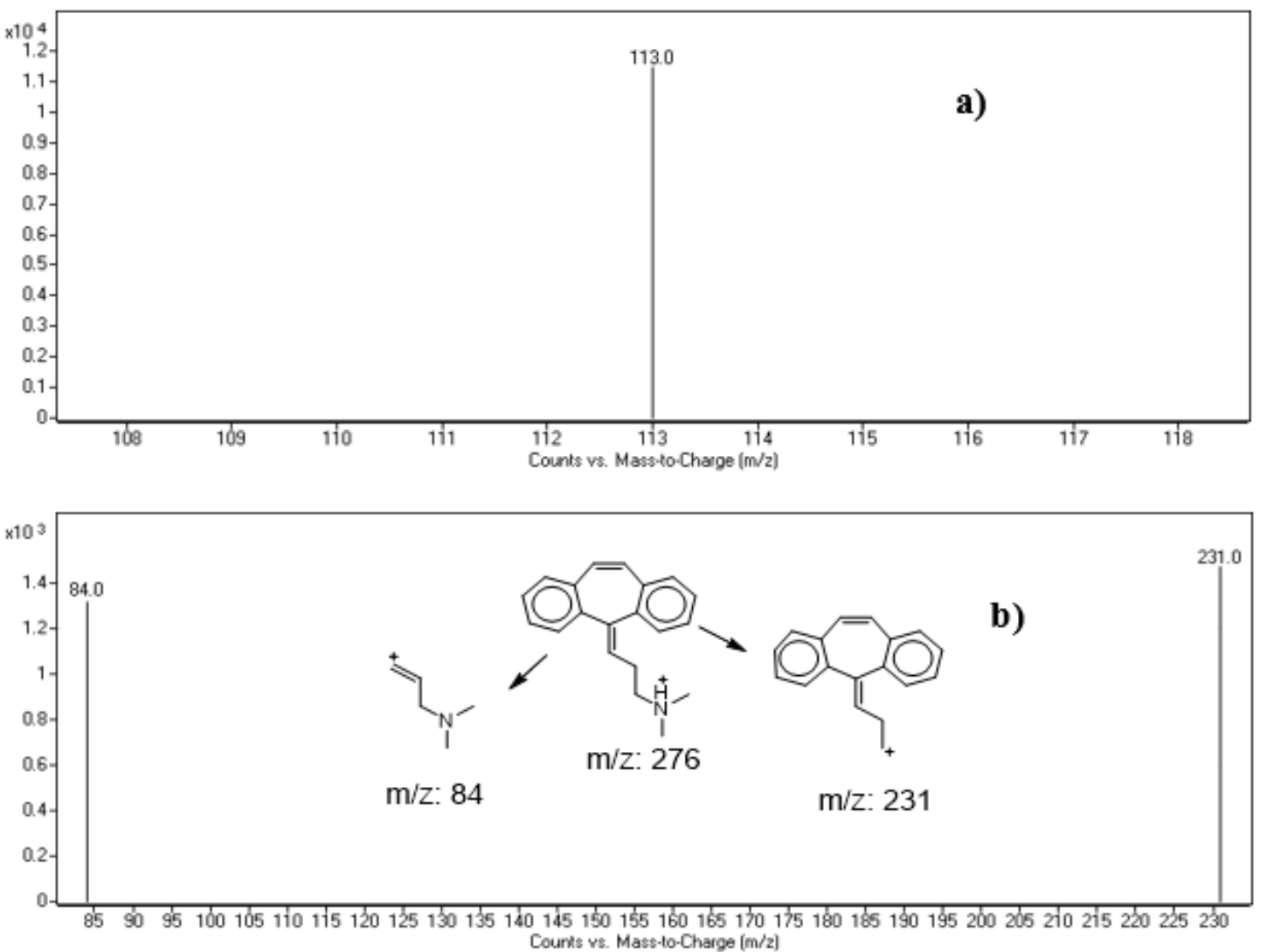

Figure 3: MRM Spectra of a) NTB and b) CBP (IS)

Table 1: Back-calculated NTB concentration of the calibration standards in plasma

\begin{tabular}{lcccc}
\hline $\begin{array}{l}\text { Nominal concentration } \\
\text { (ng } \mathbf{~ m}^{-1} \text { ) }\end{array}$ & Mean $^{\mathbf{a}}$ & Standard deviation (SD) & Precision (\%) & Accuracy (\%) \\
\hline 2 & & & & \\
\hline 4 & 2.02 & 0.11 & 5.39 & 0.95 \\
6 & 3.86 & 0.07 & 1.74 & -3.38 \\
10 & 5.93 & 0.09 & 1.51 & -1.11 \\
30 & 10.23 & 0.10 & 1.00 & 2.34 \\
50 & 28.84 & 0.42 & 1.46 & -3.86 \\
80 & 50.54 & 0.64 & 0.85 & 2.08 \\
100 & 81.73 & 0.70 & 0.77 & -0.51 \\
120 & 99.49 & 0.77 & 2.44 & -0.49 \\
150 & 119.42 & 2.91 & 0.92 & -0.05 \\
\hline
\end{tabular}

${ }^{\mathrm{a}}$ Mean of six determinations 
Table 2: Intra-day and inter-day precision and accuracy of NTB (QC) samples

\begin{tabular}{|c|c|c|c|c|c|c|}
\hline \multirow{2}{*}{ Day of analysis } & \multicolumn{6}{|c|}{ NTB measured concentration in plasma } \\
\hline & \multicolumn{2}{|c|}{ LQC (6 ng mL $\left.{ }^{-1}\right)$} & \multicolumn{2}{|c|}{ MQC (50 $\left.\mathrm{ng} \mathrm{mL}^{-1}\right)$} & \multicolumn{2}{|c|}{ HQC (120 $\left.\mathrm{ng} \mathrm{mL}^{-1}\right)$} \\
\hline & \multicolumn{2}{|c|}{6.10} & \multicolumn{2}{|c|}{50.06} & \multicolumn{2}{|c|}{119.35} \\
\hline & \multicolumn{2}{|c|}{5.92} & \multicolumn{2}{|c|}{50.10} & \multicolumn{2}{|c|}{119.53} \\
\hline & \multicolumn{2}{|c|}{6.05} & \multicolumn{2}{|c|}{50.47} & \multicolumn{2}{|c|}{116.08} \\
\hline & \multicolumn{2}{|c|}{6.01} & \multicolumn{2}{|c|}{50.07} & \multicolumn{2}{|c|}{115.65} \\
\hline & \multicolumn{2}{|c|}{6.03} & \multicolumn{2}{|c|}{50.00} & \multicolumn{2}{|c|}{116.13} \\
\hline \multirow{9}{*}{ Day 1} & \multicolumn{2}{|c|}{5.96} & \multicolumn{2}{|c|}{49.86} & \multicolumn{2}{|c|}{119.41} \\
\hline & \multicolumn{2}{|c|}{5.96} & \multicolumn{2}{|c|}{50.69} & \multicolumn{2}{|c|}{116.83} \\
\hline & \multicolumn{2}{|c|}{5.94} & \multicolumn{2}{|c|}{50.27} & \multicolumn{2}{|c|}{116.41} \\
\hline & & & & & & \\
\hline & & & & & & \\
\hline & & & & & & \\
\hline & & & & & & \\
\hline & & & & & & 52 \\
\hline & & & & & & \\
\hline & & & & & & \\
\hline Day 2 & & & & & & \\
\hline & & & & & & \\
\hline & & & & & & \\
\hline & & & & & & \\
\hline & & & & & & \\
\hline Rav 3 & & & & & & \\
\hline Day 3 & & & & & & \\
\hline & & & & & & \\
\hline & & & & & & \\
\hline Parameter & $\begin{array}{c}\text { Intra-day } \\
\text { assay }\end{array}$ & $\begin{array}{l}\text { Inter-day } \\
\text { assay }\end{array}$ & $\begin{array}{c}\text { Intra-day } \\
\text { assay }\end{array}$ & $\begin{array}{c}\text { Inter-day } \\
\text { assay }\end{array}$ & $\begin{array}{c}\text { Intra-day } \\
\text { assay }\end{array}$ & $\begin{array}{c}\text { Inter-day } \\
\text { assay }\end{array}$ \\
\hline Mean & 5.96 & 6.01 & 50.29 & 50.21 & 117.58 & 118.00 \\
\hline $\begin{array}{l}\text { Standard deviation } \\
\text { (SD) }\end{array}$ & 0.08 & 0.10 & 0.36 & 1.85 & 1.76 & 1.46 \\
\hline Precision (\%RSD) & 1.40 & 1.61 & 0.71 & 3.68 & 1.50 & 1.24 \\
\hline Accuracy (\%RE) & -0.68 & 0.10 & 0.58 & 0.43 & -2.02 & -1.67 \\
\hline
\end{tabular}

${ }^{*}$ Average of twelve determinations of day $1 .{ }^{* *}$ Average of six determinations in three consecutive days.

Table 3: NTB stability data in plasma matrix under different conditions

\begin{tabular}{|c|c|c|c|c|}
\hline $\begin{array}{l}\text { Nominal concentration } \\
\left(\text { ng. } \mathrm{mL}^{-1}\right)\end{array}$ & $\begin{array}{c}\text { Mean } \\
\left(\text { ng.mL } L^{-1}\right)\end{array}$ & $\begin{array}{c}\text { Standard } \\
\text { Deviation } \\
\text { (SD) }\end{array}$ & $\begin{array}{l}\text { Precision } \\
\text { (RSD, \%) }\end{array}$ & Accuracy (RE, \%) \\
\hline \multicolumn{5}{|l|}{ Room temp. for $8 \mathrm{~h}$} \\
\hline 6 & 19.35 & 0.28 & 1.45 & -3.23 \\
\hline 50 & 148.71 & 1.62 & 1.09 & -0.86 \\
\hline 120 & 396.96 & 3.15 & 0.79 & -0.76 \\
\hline \multicolumn{5}{|l|}{ Three freeze-thaw cycles } \\
\hline 6 & 18.71 & 0.40 & 2.13 & -6.45 \\
\hline 50 & 148.71 & 1.62 & 1.09 & -0.86 \\
\hline 120 & 396.96 & 3.15 & 0.79 & -0.76 \\
\hline \multicolumn{5}{|l|}{ Stored at $4{ }^{\circ} \mathrm{C}$ for $24 \mathrm{~h}$} \\
\hline 6 & 19.04 & 0.34 & 1.79 & -4.82 \\
\hline 50 & 148.71 & 1.62 & 1.09 & -0.86 \\
\hline 120 & 396.96 & 3.15 & 0.79 & -0.76 \\
\hline \multicolumn{5}{|c|}{ Stored at $-20^{\circ} \mathrm{C}$ for 30 days } \\
\hline 6 & 18.62 & 0.35 & 1.87 & -6.92 \\
\hline 50 & 148.71 & 1.62 & 1.09 & -0.86 \\
\hline 120 & 397.60 & 2.19 & 0.55 & -0.60 \\
\hline
\end{tabular}


In addition to the optimization of chromatographic conditions, mass spectrometric parameters were also adjusted for achieving consistent behaviour of the parent ions and the major product ions of NTB and CBP. From different modes afforded by tanden mass spectrometry, multiple reaction monitoring (MRM) mode is advantageous when compared to selected ion monitoring (SIM) in decreasing matrix effect of plasma as well as increasing sensitivity to the analyte of interest. Additionally the sensitivity and selectivity were enhanced by operating the ionization source (ESI) in positive ion mode.

For quantification of NTB and CBP, m/z 113 and 231 were selected as daughter peaks in MRM mode because they gave the highest signal intensity. While $\mathrm{m} / \mathrm{z} 84$ was utilized as a qualifier for CBP.

After method development, validation took place in terms of sensitivity, linearity, stability, selectivity, accuracy, intra-day and inter-day precision, and system suitability. The method validation was developed based on the criteria established by the recommendations of the European Medicines Agency (EMA) [10].

The limit of quantitation (LOQ) is the lowest concentration of the standard curve which can be measured with acceptable accuracy and precision for the analyte from human plasma. The limit of detection (LOD) and the limit of quantitation (LOQ) were calculated based on Eq 1.

LOQ OR LOD=(k u)M

where $k$ equal to 10 and 3.3 for LOQ and LOD respectively, $u$ is the standard deviation of the intercept of regression line and $M$ is the slope of regression line of the calibration curve.

Intra-day accuracy and precision were evaluated by repeated analysis of NTB in human plasma. The run consisted of a calibration curve plus twelve replicates of each low, medium and high quality control (QC) samples $\left(6,50,120 \mathrm{ngmL}^{-1}\right)$. Inter-day accuracy and precision were assessed by analysis of samples consisting of a calibration curve and six replicates of low, medium, and high quality control samples for NTB on three successive days. The overall precision of the method expressed as relative standard deviation and accuracy of the method expressed in term of \% error which is calculated according to Eq 2.

$\%$ Error $=[(\mathrm{A}-\mathrm{B}) / \mathrm{B}] \times 100$ where $A$ is mean measured concentration, $B$ is nominal concentration of NTB.

For assessing of NTB stability in plasma matrix, six replicates of QC samples were analyzed utilizing various storage conditions. Calculation of accuracy and precision values were carried out using freshly prepared calibration curves in plasma matrix. Estimation of NTB bench-top stability was done after $8 \mathrm{~h}$ of storing NTB QC samples at room temperature. Three freezethaw cycles were achieved to estimate NTB stability of spiked QC samples after freezing and thawing samples at $-80^{\circ} \mathrm{C}$ and room temperature respectively. Moreover, evaluation of NTB stability was performed by analyzing the spiked QC samples after one day of storing them at $4 \mathrm{o}$ $\mathrm{C}$ and after one month of their storage at $-20{ }^{\circ} \mathrm{C}$.

\section{CONCLUSION}

A rapid and validated LC-MS/MS method has been developed for the quantification of NTB in human plasma with good linearity. The assay procedure is simple for sample preparation with a short run time. Its elution is eco-friendly with regard to reduced consumption of organic solvent and low-cost. The developed method should be useful for therapeutic drug monitoring of NTB in plasma and thus for further pharmacokinetic studies of NTB.

\section{DECLARATIONS}

\section{Acknowledgement}

The authors would like to extend their sincere appreciation to Deanship of Scientific Research at King Saud University for funding Research Group no. RGP-322.

\section{Conflict of Interest}

No conflict of interest associated with this work.

\section{Contribution of Authors}

The authors declare that this work was done by the authors named in this article and all liabilities pertaining to claims relating to the content of this article will be borne by them.

\section{Open Access}

This is an Open Access article distributed under the terms of the Creative Commons Attribution License, which permits unrestricted use, 
distribution, and reproduction in any medium, provided the original work is properly credited.

\section{REFERENCES}

1. Hilberg $F$, Roth $G J$, Krssak $M$, Kautschitsch $S$, Sommergruber $W$, Tontsch-Grunt $U$, Garin-Chesa $P$, Bader G, Zoephel A, Quant J. BIBF 1120: triple angiokinase inhibitor with sustained receptor blockade and good antitumor efficacy. Cancer Res. 2008; 68(12): 4774-4782.

2. McCormack PL. Nintedanib: first global approval. Drugs 2015; 75(1): 129-139.

3. Wollin L, Wex E, Pautsch A, Schnapp G, Hostettler KE, Stowasser S, Kolb M. Mode of action of nintedanib in the treatment of idiopathic pulmonary fibrosis. Eur Respir J. 2015: ERJ-01749-2014.

4. Mazzei ME, Richeldi L, Collard HR. Nintedanib in the treatment of idiopathic pulmonary fibrosis. Ther Adv Respir Dis. 2015; 9(3): 121-129.

5. Karimi-Shah BA, Chowdhury BA. Forced Vital Capacity in Idiopathic Pulmonary Fibrosis-FDA Review of
Pirfenidone and Nintedanib. N Engl J Med. 2015; 372(13): 1189-1191.

6. Syrios J, Nintos G, Georgoulias V. Nintedanib in combination with docetaxel for second-line treatment of advanced non-small-cell lung cancer. Expert Rev Anticancer Ther. 2015; 15(8): 875-884.

7. Lin D, Qiao L-m, Zhang Y-n, Liu Y, Liu X-s. Simultaneous determination of nintedanib and its metabolite by UPLCMS/MS in rat plasma and its application to a pharmacokinetic study. J Pharm Biomed Anal. 2016; 117: 173-177.

8. Xu X-w, Su $X-j$, Zhang $Y-n$, Zheng $X-k$, Lv P-f, Hu J. Simultaneous determination of nintedanib and its metabolite BIBF 1202 in different tissues of mice by UPLC-MS/MS and its application in drug tissue distribution study. J Chromatogr B Analyt Technol Biomed Life Sci. 2015; 1002: 239-244.

9. Xu D, Zhang Y, Dai J, Bai Y, Xiao Y, Zhou M-t. A fast, sensitive, and high throughput method for the determination of nintedanib in mouse plasma by UPLCMS/MS. Anal Methods 2015; 7(16): 6561-6565.

10. Committee for Medicinal Products for Human Use (CHMP), Guideline on Bioanalytical Method Validation, European Medicines Agency, 2011. 